\title{
Phytochemical Analysis and Antibacterial Activities of Tamarix dioica Extracts
}

\author{
Saddam Hussain Bughio ${ }^{1}$, Muhammad Qasim Samejo ${ }^{1 *}$, Shahabuddin Memon ${ }^{2}$, \\ Ghulam Zuhra Memon ${ }^{1}$, Humaira Khan ${ }^{1}$, Nusrat Naeem Memon ${ }^{1}$, Saba Naz ${ }^{1}$ and \\ Jamil-ur-Rehman Memon ${ }^{1}$ \\ ${ }^{1}$ Dr. M. A. Kazi Institute of Chemistry, University of Sindh, Jamshoro 76080, Pakistan. \\ ${ }^{2}$ National Center of Excellence in Analytical Chemistry, University of Sindh, Jamshoro 76080, Pakistan. \\ *Corresponding Author Email: muhammadqasimsamejo@yahoo.com \\ Received 26 October 2019, Revised 08 February 2021, Accepted 26 March 2021
}

\begin{abstract}
The objective of this study was to investigate the impact of phytochemical analysis and the antibacterial activity of extracts of stem, flowers and leaves of Tamarix dioica Roxb. ex Roth. Four solvents namely, diethyl ether, ethyl acetate, methanol and acetone were selected to obtain extracts from different parts of the plant. The organic solvent extracts were investigated for phytochemical analysis and antibacterial activity against two bacterial strains, namely Escherichia coli and Staphylococcus aureus. The result of phytochemicals revealed the presence of various constituents, such as phlobatannins, tannins, saponins, alkaloids, phenols, proteins, terpenoids, flavonoids and steroids by using standard procedures. Most of these components were present in methanol and ethyl acetate extract. Therefore, four out of two extracts, such as methanol and ethyl acetate extracts from stems, flowers, and leaves, were used to test their evidence of antibacterial activity. From this, it was observed that the methanol extracts of stem, flowers and leaves of $T$. dioica were highly effective together with $E$. coli and $S$. aureus with a minimum inhibitory concentration (MIC) value of $500 \mu \mathrm{g} / \mathrm{mL}$. Considering that the ethyl acetate (EA) extracts from the stem, flowers and leaves of $T$. dioica were examined to be ineffective against $E$. coli and $S$. aureus and MIC values were not observed in two strains of bacteria.
\end{abstract}

Keywords: Tamarix dioica extracts, Phytochemical analysis, Antibacterial activities.

\section{Introduction}

Plants are important components of the universe and used to cure of several diseases from ancient time. According to the report of the world health organization (WHO), approximately $80 \%$ of the world population depends on traditional medicine for its treatment and physical health [1]. These plants have opened the window to the progress of numerous therapeutic agents [2]. In Islam, diseases are treated in two ways, the first is to treat oneself with prayer, and the second is to treat illnesses through medicine [3]. Plants contain a lot of phytochemicals such as amino acids, saponins, tannins, glycosides, alkaloids, fatty acids, sterols, flavonoids and terpenes [4]. These phytochemicals protect plants themselves, but recent research reveals that many of these phytochemicals can protect animals and humans against various diseases [5], including cancer, diabetes and cardiovascular disorders [6]. Phytochemicals are non-nutritive, natural, secondary metabolites and biologically active compounds. However, a large proportion of 
phytochemicals has not yet been identified and is still identified by the scientific community [7-9].

T. dioica with the family of Tamaricaceae (common name: Lai) that grows from 1 to $18 \mathrm{~m}$ of height includes 60 different species. It is a small tree or evergreen shrub and has vaginate leaves, purple flowers and reddish bark. The Tamarix genus feeds on approximately around 250 species of invertebrates and cattle and camels [10]. Although, Tamarix hold the height of a small tree and has a deep taproot that can extend 25 to 30 meters below the earth's surface. Mostly, tree is found in Pakistan, Afghanistan, India, Bangladesh, Iran, Bhutan, Nepal, Myanmar and Kashmir. In Pakistan, it is found in Sindh and Khyber Pakhtun Khwa (KPK) provinces [11].

The leaves of $T$. dioica are used as a diuretic (promotes diuresis), carminative and to heal irritation of the liver and spleen. In addition, this plant is used as a constringent for symptoms such as vaginal discharge [12]. $T$. dioica has demonstrated antibacterial activity against Pseudomonas aeruginosa and Klebsiella pneumonia as well as antifungal activity against three microorganisms, Candida glabrata, Aspergillus fumigates and Trichophyton rubrum [13]. Survey of the literature shows that little work has been found in the phytochemical trace and antibacterial activities of $T$. dioica. Taking into account all these facts, the current study was designed to identify the existence of different phytochemicals in three different parts of $T$. dioica (such as stem, flowers and leaves) and the determination of their antibacterial activity.

Materials and Methods

Chemicals and Reagents

All chemicals (Sigma-Aldrich Chemical Company) were used for biological activity and analysis of phytochemicals. Glacial acetic acid, Chloroform, dimethyl sulfoxide, diethyl ether, ethyl acetate, methanol, acetone, ferric chloride, sulfuric acid, hydrochloric acid, sodium hydroxide, copper(II)sulphate, iodine, potassium iodide, Benedict reagent, Wagner's reagent, Ninhydrin reagent, Fehling solution, Muller Hinton agar (MHA) and distilled water.

\section{Plant Materials (Collection \& Identification)}

The $T$. dioica collected from Sindh University, New Campus, Jamshoro, Sindh, Pakistan, in the month of September and November 2019 (Longitude: 25.430387 and latitude: 68.280861) and deposited in the herbarium of the Institute of Plant Sciences (IPS), University of Sindh (UoS), Jamshoro, Pakistan. A file and voucher specimen (2671317) of the plant provided by IPS taxonomist, UoS, Jamshoro.

\section{Drying and Crushing of Plant Material}

The parts of $T$. dioica were washed thrice with sterilized water to remove dust and contaminated particles, dried in the shade for 15 days, all parts were individually crushed with an electric mixer and the powder it was placed in different containers before analysis.

\section{Preparation of Different Extracts with Various Solvents}

Taken $10 \mathrm{~g}$ powder of each part of $T$. dioica (e.g. stem, flowers, and leaves) and separately macerated with four different solvents namely; methanol, diethyl ether, acetone and ethyl acetate for seventy two hours. Whatman no. 1, the filter paper was used for filtration processes, and then all the filtrates were examined for phytochemicals and bacterial strains (E. coli and $S$. aureus). 
The Phytochemical Study of Different Crude Extracts

To identify the phytochemicals in the crude extracts of $T$. dioica, the following procedures were used; the presence of these phytochemicals was detected by color test [4].

\section{Analysis Procedures \\ Phlobatannins test}

$1 \mathrm{~mL}$ of filtrate was boiled with $1 \%$ aqueous $\mathrm{HCl}$ (hydrochloric acid). The appearance of a reddish Color confirms the existence of phlobatannins.

\section{Alkaloids test (Wagner's reagent)}

(Wagner's reagent composition: $1.27 \mathrm{~g}$ iodine $+2 \mathrm{~g}$ potassium iodide + distilled water to make final volume $100 \mathrm{~mL}$ ) $0.5 \mathrm{~g}$ of the extract was taken in the test tube and added 2 $\mathrm{mL}$ of Wagner's reagent, after few min reddish brown color appeared indicated the presence of alkaloids.

\section{Carbohydrates test (Benedict's test)}

(Benedict reagent composition: Solution A: $100 \mathrm{~g}$ sodium carbonate $+173 \mathrm{~g}$ sodium citrate $+800 \mathrm{~mL}$ water, dissolve \& boil to make solution clear Solution B: $17.3 \mathrm{~g}$ of copper sulphate dissolved in $100 \mathrm{~mL}$ distilled water)

Benedict reagent (5-8 drops) were added to $2 \mathrm{~mL}$ of each extracts, boiled using a water bath for 5 min cooled and reddish brown precipitates were observed.

\section{Cardiac glycosides test (Keller Kelliani's test)}

Glacial acetic acid $(2 \mathrm{~mL})$ and ferric chloride $(1 \mathrm{~mL})$ were added to $5 \mathrm{~mL}$ of each extract. The contents were heated, cooled and then the contents were poured into another test tube containing $2 \mathrm{~mL}$ conc. sulfuric acid with care. After some time, a purple ring appeared, which may confirmed the presence of glycosides.

\section{Test for flavonoids}

$20 \% \mathrm{NaOH}$ (few drops) was added in $2 \mathrm{ml}$ of each extract; the yellow color appeared and turned colorless on adding dilution. $\mathrm{HCl}$ confirmed the presence of flavonoids.

\section{Phenols test or Ferric chloride test}

Few drops of ferric chloride (5\% aqueous solution) were added to each plant extract, the black/blue color appeared in the last one indicates the presence of phenol.

Amino acids and proteins test or $1 \%$ ninhydrin solution

5-6 drops of Ninhydrin reagent $(10 \mathrm{mg}$ ninhydrin $+200 \mathrm{~mL}$ acetone) was added to each plant extract $(2 \mathrm{~mL})$, then the content was boiled for a few minutes, the purple color appeared confirmed the presence of amino acid.

\section{Saponins test or Foam test}

$3 \mathrm{~mL}$ of distilled water was added in each plant extract, the mixture was shaken vigorously for few $\mathrm{min}$, the foam that appeared at the surface confirmed the presence of saponins.

\section{Tannins test or Braymer's test}

Ferric chloride (10\%; few drops) was added to each $2 \mathrm{~mL}$ plant part extract and observed. The appearance of green/blue color confirmed the presence of tannins. 


\section{Terpenoids test or Salkowki's test}

Chloroform $(1 \mathrm{~mL})$ and conc. Sulfuric acid (few drops) was added in $2 \mathrm{~mL}$ of each part of plant extract and then observed. Reddish-brown precipitates indicated the presence of terpenoids.

\section{Proteins test or Biuret test}

5-7 drops of $1 \% \mathrm{Cu}\left(\mathrm{SO}_{4}\right)_{2}$ and 5-7 drops of $5 \% \mathrm{NaOH}$ were treated with $2 \mathrm{~mL}$ of filtrate. The violet color confirmed the presence of proteins.

\section{Determination of antimicrobial activities}

The disk diffusion process in Muller Hinton (MHA) medium was used for the antibacterial activity of extracts of stems, flowers and leaves of $T$. dioica. The method to check the antibacterial activity of the three parts was favored with the help of the American Type Culture Collection (ATCC); antibacterial activity against two different microbes was planned; E. coli and S. aureus. MHA medium was used for the growth of microorganism species [14-15].

Three successive concentrations of 1000,750 and $500 \mu \mathrm{g} / \mathrm{mL}$ was prepared in dimethyl sulfoxide (DMSO) to test the antibacterial activity of extracts. Therefore,
DMSO was used as a negative control. Bacterial suspensions were expanded into solid Petri dishes (90 $\mathrm{mm}$ in size) using a sterile cotton swab moistened with bacterial suspensions and adjusted to $10^{6} \mathrm{CFU} / \mathrm{mL}$ [16].

Then, moistened Whatman No. 1 filter paper (6 mm diameter) with $20 \mu \mathrm{L}$ of different concentrations was placed on the surface of microbial Petri dishes and placed in an incubator at a temperature of $37^{\circ} \mathrm{C}$ and time period for $24 \mathrm{~h}$. Antibacterial activity of the extracts (stem, flower, and leaf) was recorded against each microbial species by measuring the area of diameter inhibition in millimeters around the discs and the value of MIC was determined. All experiments were carried out three times [17-19].

\section{Results and Discussion \\ The Analysis of Phytochemicals}

Phytochemical examination of plant extracts gave an idea of the presence of what type of class of compounds are present in selected plant. For qualitative analysis of $T$. dioca extract, total of ten phytochemicals were checked such as alkaloids, steroids, glycosides, tannins, phenols, flavonoids, protein, saponins, terpenoids and phlobatannins. The obtained results are tabulated in Table 1.

Table 1. Phytochemical analysis of various extract of $T$. dioica parts.

\begin{tabular}{|c|c|c|c|c|c|c|c|c|c|c|c|c|}
\hline \multirow[b]{2}{*}{ Phytochemicals } & \multicolumn{4}{|c|}{ Flowers } & \multicolumn{4}{|c|}{ Stem } & \multicolumn{4}{|c|}{ Leaves } \\
\hline & $D E$ & $E A$ & $M E$ & $A C$ & $D E$ & $E A$ & $M E$ & $A C$ & $D E$ & $E A$ & $M E$ & $A C$ \\
\hline Phlobatannins & - & - & - & - & - & - & + & + & - & - & - & - \\
\hline Glycosides & - & - & - & - & - & - & - & - & - & - & - & - \\
\hline Saponins & + & + & + & + & + & + & + & + & + & + & + & + \\
\hline Tannins & - & + & ++ & + & - & + & + & + & - & + & ++ & + \\
\hline Alkaloids & + & + & ++ & + & + & + & ++ & + & + & + & ++ & + \\
\hline Phenols & - & + & ++ & + & - & + & ++ & + & - & + & ++ & + \\
\hline Proteins & - & + & + & + & - & - & - & - & - & + & + & + \\
\hline Flavonoids & + & + & ++ & + & + & + & ++ & + & + & + & ++ & + \\
\hline Terpenoids & - & + & + & + & - & + & + & + & - & + & + & + \\
\hline Steroids & - & + & ++ & + & + & + & + & + & - & + & ++ & + \\
\hline
\end{tabular}


Qualitative phytochemical analysis made for the flowers, leaves and stem parts of $T$. dioica revealed the presence of majority of secondary metabolites as shown in Table 1 . The majority of these metabolites are present in all parts of $T$. dioica solvent extracts. As we all know that phytochemicals have therapeutic and biological properties, so dioica species is expected to have many medicinal uses.

The extraction yield was calculated and the methanol extract was found to have a higher yield than other non-polar solvents, it may be due to the high polarity of the methanol solvents. It can be concluded that the methanol solvent has a higher power to remove the components of plant species than non-polar solvents. It means that the high level of the polarity of the solvent plays an important role in extracting the chemical components of the plants [20]. The absence of steroids in the extract of diethyl ether in flowers and leaves may be due to a low concentration of steroids in these parts that could not be detected. The recovery of the plant's phytochemical can be affected by the chemical properties of the phytochemicals, the dielectric constant, and the chemical composition of the organic solvents. Our previous work reported by Samejo et al., [4], which also showed the analysis of phytochemicals, but in this work, the choice of solvent is different from the present work.
The tabulated results in Table-1 revealed the presence of these phytochemicals such as alkaloids, steroids, glycosides, tannins, phenols, flavonoids, proteins, saponins, terpenoids and phlobatannins, which are well known to possess physiological and medicinal properties [21]. Literature survey revealed that steroids, flavonoids, alkaloids have antibacterial, analgesic and antispasmodic properties. Phenolic compounds have medicinal value such as anti-carcinogen, apoptosis, anti-inflammation, anti-aging, antiatherosclerosis, cardiovascular protection [21].

\section{Determination of antibacterial activities}

The results of the antibacterial activity are shown in Table 2. The general results obtained from the plant parts of the methanol and ethyl acetate extract of $T$. dioica do not represent an interesting antibacterial activity against all the strains tested, including $S$. aureus and E. coli. The methanol extract shows some antibacterial activity, but the ethyl acetate extract shows no activity, this may be due to a lower extraction power of antibiotic compounds. Table 2 shows that the MICs of the methanolic extracts of aerial parts of $T$. dioica were found to be higher than the ethyl acetate extract that does not have MIC.

Table 2. Inhibition zones ( $\mathrm{mm}$ in diameters) for antibacterial activities of methanol and ethyl acetate extracts of stem, flowers and leaves of T. dioica.

\begin{tabular}{|c|c|c|c|c|c|c|}
\hline \multirow{3}{*}{$\begin{array}{c}\text { Solvents } \\
\text { Methanol } \\
\text { Con. }(\mu \mathrm{g} / \mathrm{mL})\end{array}$} & \multicolumn{6}{|c|}{ Zone of inhibition in $\mathrm{mm} \pm \mathrm{SD}$} \\
\hline & \multicolumn{3}{|c|}{ E. coli $\quad(\mathrm{MIC} 500 \mu \mathrm{g} / \mathrm{mL})$} & \multicolumn{3}{|c|}{ S. aureus $\quad(\mathrm{MIC} 500 \mu \mathrm{g} / \mathrm{mL})$} \\
\hline & Stem & Flowers & Leaves & Stem & Flowers & Leaves \\
\hline 1000 & $9 \pm 0.01$ & $11 \pm 0.03$ & $9 \pm 0.02$ & $11 \pm 0.02$ & $13 \pm 0.03$ & $8 \pm 0.02$ \\
\hline 750 & $7 \pm 0.01$ & $8 \pm 0.02$ & $6 \pm 0.00$ & $6 \pm 0.02$ & $8 \pm 0.01$ & $5 \pm 0.00$ \\
\hline 500 & $2 \pm 0.00$ & $3 \pm 0.00$ & $2 \pm 0.00$ & $3 \pm 0.001$ & $4 \pm 0.01$ & $3 \pm 0.00$ \\
\hline Control & - & - & - & - & - & - \\
\hline Ethyl acetate & \multicolumn{3}{|c|}{$\begin{array}{c}\text { E. coli } \\
(\mathrm{MIC} 0 \mu \mathrm{g} / \mathrm{mL})\end{array}$} & \multicolumn{3}{|c|}{$\begin{array}{c}\text { S. aureus } \\
(\mathrm{MIC} 0 \mu \mathrm{g} / \mathrm{mL})\end{array}$} \\
\hline Con. $(\mu \mathrm{g} / \mathrm{mL})$ & Stem & Flowers & Leaves & Stem & Flowers & Leaves \\
\hline 1000 & - & - & - & - & - & - \\
\hline 750 & - & - & - & - & - & - \\
\hline 500 & - & - & - & - & - & - \\
\hline Control & - & - & - & - & - & - \\
\hline
\end{tabular}


In recent years, there has been a great demand for research on phytochemicals that possess antimicrobial properties due to their potential use in treating various chronic and infectious diseases.

$\begin{aligned} & \text { Reports of the World Health } \\ & \text { Organization (WHO) showed that }\end{aligned}$
approximately $50 \%$ of E. coli and S. aureus
were resistant to most antibiotics, such as
cephalosporins. The increasing trend in
developing antibiotic resistance can be
attributed to frequent, unnecessary, and abuse
of antibiotics and prolonged hospitalization
[22].

\section{Conclusion}

The study suggests that the $T$. dioica has the potential for further exploration to identify phytochemicals and antibacterial compounds. The antibacterial activities of methanol extract provide scientific support for its traditional use in folk medicine to treat various diseases.

\section{Acknowledgement}

We are very grateful to Dr. M. A. Kazi Institute of Chemistry, Sindh University, Jamshoro and National Centre of Excellence in Analytical Chemistry, Sindh University, Jamshoro for the necessary facilities.

\section{Conflict of Interest}

The authors declare that there is no conflict of interest.

\section{References}

1. Z. Shewamene, T. Dune and C. A. Smith, BMC Complement. Altern. Med., $20(2020) 1$. doi.org/10.1186/s12906-020-2852-6
2. S. Goyal, N. Gupta, S. Chatterjee and S. Nimesh, Curr. Top. Med. Chem., 17 (2017) 96. doi:10.2174/1568026616666160530154 $\underline{407}$

3. Aberoumand, Int. J. Food Sci. Nutr., 2 (2012) 16. doi: 10.5923/j.food.20120202.01

4. M. Q. Samejo, A. Sumbul, S. Shah, S. B. Memon, and S. Chundrigar, J. Pharm. Res., 7 (2013) 181.

5. A. Kumar, R. Ilavarasan, T. Jayachandran, M. Decaraman, P. Aravindhan, N. Padmanabhan and M. R. V. Krishnan, Pak. J. Nutr., 8 (2009) 83. doi: 10.3923/pjn.2009.83.85

6. B. Pagliaro, C. Santolamazza, F. Simonelli and S. Rubattu, BioMed Res. Int., 2015 (2015) 1. https://doi.org/10.1155/2015/918069

7. C. Leitzmann, Complement. Med. Res., 23 (2016) 69. doi: $10.1159 / 000444063$

8. A. Altemimi, N. Lakhssassi, A. Baharlouei, D. G. Watson and D. A. Lightfoot, Plants, 6 (2017) 42. doi: $10.3390 /$ plants6040042

9. S. K. Chang, C. Alasalvar and F. Shahidi, J. Funct. Foods, 21 (2016) 113. doi:10.1016/j.jff.2015.11.034

10. B. R. Baum, Baileya, 15 (1967) 19. https://link.springer.com/article/10.1672/ 0277-5212(2001)021[0240:TGATNM] 2.0.CO;2

11. S. Khan, G. M. Khan, S. Mehsud, A. Rahman and F. Khan, Gomal J. Med. Sci., 2 (2004) 40. doi: $10.46903 / \mathrm{gjms} / 2$

12. S. Khan, F. Ullah and T. Mahmood, Turk. J. Biol., 37 (2013) 329. doi:10.3906/biy-1204-18

13. S. H Bughio, M. Q. Samejo, S. Memon, S. Bano, M. A. Mughal and A. A. Memon, Int. J. Food Prop., (2017) 20(sup3), S2660. 
https://doi.org/10.1080/10942912.2017.1 387138

14. C. Valgas, S. M. D. Souza, E. F. Smânia and A. Smânia Jr, Braz. J. Microbiol., 38 (2007) 369.

http://dx.doi.org/10.1590/S151783822007000200034

15. S. Rawat, R Saini and A. Sharma, Int. Res. J. Pharm., 4 (2013) 53. doi:10.7897/2230-8407.041212

16. M. Bouchekrit, H. Laouer, M. Hajji, M. Nasri, S. A. Haroutounian and S. Akkal, Asian Pac. J. Trop. Biomed., 6 (2016) 851.

https://doi.org/10.1016/j.apjtb.2016.07.014

17. P. S. Pavithra, N. Sreevidya and R. S. Verma, J. Ethnopharmacol., 124 (2009) 151.

doi:10.1016/j.jep.2009.04.016

18. Q. K. Panhwar and S. Memon, J. Coord. Chem., 64 (2011) 2117.

https://doi.org/10.1080/00958972.2011.5 $\underline{90192}$
19. S. Memon, A. A. Chandio, A. A. Memon, Q. K. Panhwar, S. M. Nizamani, A. A. Bhatti and N. A. Brohi, Polycyclic Aromat. Compd., 37 (2016) 362.

doi:10.1080/10406638.2015.1125375

20. J. Senguttuvan, S. Paulsamy, and K. Karthika. Asian Pac. J. Trop. Biomed., 4 (2014) S359. doi: 10.12980/APJTB.4.2014C1030

21. P. Shrestha, S. Adhikari, B. Lamichhane and B. G. Shrestha. IOSR J. Environ. Sci. Toxicol. Food Technol., 1 (2015) 11. https://www.researchgate.net/publication 1288833014 Phytochemical Screening of the Medicinal_Plants_of_Nepal

22. N. M. Atef, S. M. Shanab, S. I. Negm and Y. A. Abbas, Bull. Natl. Res. Cent., 43 (2019) 144.

doi.org/10.1186/s42269-019-018 